\title{
Comparative effectiveness and tolerance of treatments for Helicobacter pylori: systematic review and network meta-analysis
}

\author{
Bao-Zhu Li, ${ }^{1,2}$ Diane Erin Threapleton, ${ }^{3}$ Ji-Yao Wang, ${ }^{4}$ Jian-Ming Xu, ${ }^{5}$ Jin-Qiu Yuan, ${ }^{3}$ Chao Zhang, ${ }^{1,2}$ \\ Peng Li, ${ }^{1,2}$ Qian-Ling Ye, ${ }^{6}$ Biao Guo, ${ }^{6}$ Chen Mao, ${ }^{3,7}$ Dong-Qing Ye ${ }^{1,2}$
}

For numbered affiliations see end of article.

Correspondence to: D-QYeydq@ahmu.edu.cn Additional material is published online only. To view please visit the journal online (http://dx.doi. org/10.1136/bmj.h4052) Cite this as: $B M / 2015 ; 351:$ h4052 doi: 10.1136/bmj.h4052

Accepted: 14 July 2015

\section{ABSTRACT}

OBJECTIVE

To determine the most efficacious treatment for eradication of Helicobacter pylori with the lowest likelihood of some common adverse events among pre-recommended and newer treatment regimens.

DESIGN

Systematic review and network meta-analysis.

DATA SOURCES

Cochrane Library, PubMed, and Embase without language or date restrictions.

STUDY SELECTION

Full text reports of randomised controlled trials that compared different eradication treatments for $\mathrm{H}$ pylori among adults.

RESULTS

Of the 15565 studies identified, 143 were eligible and included. Data on 14 kinds of treatments were available. Of 91 possible comparisons for the efficacy outcome, 34 were compared directly and the following treatments performed better: seven days of concomitant treatment (proton pump inhibitor and three kinds of antibiotics administered together), 10 or 14 days of concomitant treatment, 10 or 14 days of probiotic supplemented triple treatment (standard triple treatment which is probiotic supplemented), 10 or 14 days of levofloxacin based triple treatment (proton pump inhibitor, levofloxacin, and antibiotic

\section{WHAT IS ALREADY KNOWN ON THIS TOPIC}

The efficacy of standard triple treatment for Helicobacter pylori eradication has decreased and many novel treatment regimens have been introduced to increase the eradication rates

Direct comparisons between common treatments indicate higher effectiveness for some treatments

Previous treatment comparisons and attempts to identify optimal treatments are limited to the direct comparisons that have been examined within clinical trials and it is not possible to quantify relative effectiveness for all potential treatments

\section{WHAT THIS STUDY ADDS}

Among 14 well established or newer treatment regimens for $\mathrm{H}$ pylori eradication, the previously recommended seven days of standard triple treatment was the least effective in intention to treat analysis

A relative rank of the regimens was established and indicates that the most effective are concomitant treatments, 10 or 14 days of probiotic supplemented triple treatment, 10 or 14 days of levofloxacin based triple treatment, 14 days of hybrid treatment, and 10 or 14 days of sequential treatment

Prolonging treatments can enhance eradication rates but seemed to increase the risk of adverse events administered together), 14 days of hybrid treatment (proton pump inhibitor and amoxicillin used for seven days, followed by a proton pump inhibitor, amoxicillin, clarithromycin, and 5-nitroimidazole for another seven days), and 10 or 14 days of sequential treatment (five or seven days of a proton pump inhibitor plus amoxicillin, followed by five or seven additional days of a proton pump inhibitor plus clarithromycin and 5-nitroimidazole or amoxicillin). In terms of tolerance, all treatments were considered tolerable, but seven days of probiotic supplemented triple treatment and seven days of levofloxacin based triple treatment ranked best in terms of the proportion of adverse events reported.

\section{CONCLUSION}

Comparison of different eradication treatments for H pylori showed that concomitant treatments, 10 or 14 days of probiotic supplemented triple treatment, 10 or 14 days of levofloxacin based triple treatment, 14 days of hybrid treatment, and 10 or 14 days of sequential treatment might be better alternatives for the eradication of $\mathrm{H}$ pylori.

\section{Introduction}

Although Helicobacter pylori is thought to have infected humans for more than 58000 years, it was first isolated in $1982 .^{1-3}$ It is a Gram negative bacterium found on the luminal surface of the gastric epithelium. ${ }^{4} \mathrm{H}$ pylori is a potentially curable cause of a diverse spectrum of diseases such as dyspepsia, peptic ulcer disease, gastric mucosa associated lymphoid tissue lymphoma, and gastric cancer. ${ }^{56}$ Surprisingly, a series of extra-gastric and even extra-digestive diseases, including haematological disorders such as idiopathic thrombocytopenic purpura and iron deficiency anaemia, cardiovascular diseases, as well as neurological disorders are associated with $\mathrm{H}_{\text {pylori. }}{ }^{7}$ On a global scale, $H$ pylori is the most infectious human pathogen, affecting about 50\% of the population. ${ }^{5}$ In northern Europe and North America, only one third of adults have this bacterium, whereas in southern and eastern Europe, South America, and Asia, more than $50 \%$ of people are estimated to be infected. ${ }^{8} \mathrm{H}$ pylori occurs commonly in developing countries, whereas the infection rates are decreasing in developed countries, ${ }^{9}$ potentially indicating that socioeconomic status and living standards might play roles in the distribution of the infection. ${ }^{910}$ Initially, antibiotic treatment was popular and effective. ${ }^{11}$ In the early 21st century, European guidelines on the management of $H$ pylori infection recommended a "standard triple treatment" composed of a proton pump inhibitor plus 
clarithromycin, together with amoxicillin or metronidazole. ${ }^{11}$ Ranitidine bismuth citrate based triple treatment, including ranitidine bismuth citrate together with any two of amoxicillin, clarithromycin, and metronidazole has proved to have similar efficacy as the standard triple treatment. ${ }^{11} 12$ However, in less than a decade the effectiveness of the most commonly recommended treatments declined to unacceptably low levels, mainly as a result of the development of resistance to antibiotics. ${ }^{13}$

Treatment regimens have been evolving to find the most effective approaches. Some researchers showed a sequential treatment consisting of five days of a proton pump inhibitor plus amoxicillin followed by five additional days of a proton pump inhibitor plus clarithromycin and 5-nitroimidazole or amoxicillin to be an alternative approach. ${ }^{14-16}$ A bismuth based quadruple treatment including bismuth, a proton pump inhibitor, and two antibiotics was also accepted as an alternative first line treatment in many studies. ${ }^{14} 17$ Concomitant treatment with a proton pump inhibitor and three different antibiotics also showed acceptable efficacy in some circumstances. ${ }^{17}$ In this regimen, all drugs are given concomitantly and not in sequence. ${ }^{17}$ Some researchers believe that the principal advantage of this regimen is the worldwide availability of antibiotics, compared with bismuth compounds. ${ }^{17}$ In addition, the antibiotic selection or duration of treatment of this regimen is not standardised. ${ }^{17}$ Additionally, levofloxacin is an effective alternative to current standard antibiotics and tackles the primary resistance to macrolides and nitroimidazoles. ${ }^{18}$ Therefore several studies also recommended a levofloxacin based triple treatment, containing a proton pump inhibitor, levofloxacin, and one antibiotic. ${ }^{18}$ Previous studies reported that adding probiotics improved the effectiveness of $H$ pylori eradication during standard triple treatment in some circumstances. ${ }^{1920}$ Therefore a probiotic supplemented triple treatment has also been considered as a treatment option. ${ }^{19}$ A novel hybrid treatment consisting of a dual treatment with a proton pump inhibitor and amoxicillin for seven days, followed by a concomitant quadruple treatment with a proton pump inhibitor, amoxicillin, clarithromycin, and 5-nitroimidazole for another seven days produces high eradication rates and represents a promising first line treatment option. ${ }^{7}$ The standard triple treatment, ranitidine bismuth citrate based triple treatment, bismuth based quadruple treatment, concomitant treatment, levofloxacin based triple treatment, and probiotic supplemented triple treatment can be used for seven days and can be extended to 10 or 14 days. The sequential treatment is generally used for 10 days and can be extended to 14 days. The hybrid treatment is commonly used for 14 days. According to previous meta-analyses, extending treatment delivery could enhance treatment effects in some circumstances. ${ }^{521}$

Treatment of this widespread infection remains an ongoing challenge, given the estimated rates of infection in populations and the growing resistance of bacteria to antibiotics. Many treatment approaches have been developed, but it is unknown which eradication treatments are more effective and also tolerable. Previous meta-analyses of $H$ pylori eradication treatments used conventional methods ${ }^{61822-26}$ rather than network meta-analyses. In the conventional approach, only direct comparisons between treatments are possible where these have been reported in studies. This limits any conclusion about the relative efficacy and tolerance of treatments that have not been directly compared in existing studies. ${ }^{27}$ Network meta-analyses permit both direct and indirect comparisons across treatments, provided that a common comparator exists. ${ }^{2728}$ We conducted a systematic review and network meta-analysis to compare the efficacy and tolerance among different treatments for the eradication of $\mathrm{H}$ pylori infection.

\section{Methods}

\section{Data sources and searches}

On 20 December 2013 we searched the Cochrane Library, PubMed, and Embase using pre-established search terms that consisted of three parts (strategies for eradication treatment, $\mathrm{H}$ pylori, and a specific filter for randomised controlled trials). We used keywords in combination with both MeSH terms and text words. The search terms included (Helicobacter pylori OR Helicobacter OR Helicobacter infection OR Helicobacter* OR pylori OR Helicobacter pylori (MeSH)), and (eradication OR disease eradication (MeSH) OR treatment OR therapy). We excluded second line, third line, rescue, or salvage treatments. There was no limitation on language. To identify eligible studies we manually checked the reference lists of the included studies.

\section{Study selection}

Two researchers (BZL and CZ) initially screened the citation titles and abstracts. The full text versions of any study of potential relevance were then screened independently in triplicate. Disagreements were resolved through discussions. If discrepancies still existed, we sought the opinions of another two researchers for further discussion.

Included studies were full text reports of randomised controlled trials that compared different treatments for the eradication of $H$ pylori. The included studies met several criteria: comparisons among the following eradication treatments: standard triple treatment, ranitidine bismuth citrate based triple treatment, bismuth based quadruple treatment, concomitant treatment, levofloxacin based triple treatment, probiotic supplemented triple treatment, sequential treatment, and hybrid treatment; mean or median age of patients with $H$ pylori was more than 18 years; patients were free of comorbidities such as renal failure or cancer; eradication assessments were carried out at least four weeks after the end of treatment; only full articles were included to lower the risk of bias; and an intention to treat analysis had to be reported to present the frequency of $H$ pylori eradication. Exclusion criteria were: patients had received previous treatment for eradication of $H$ pylori; abstracts presented at conferences and published abstracts; studies with interventions of 
different length other than 7, 10, or 14 days; and letters, commentaries, editorials, and reviews. When multiple publications existed for the same study, we included the most comprehensive report or the publication with more complete outcome data.

\section{Patient involvement}

There was no patient involvement in this study.

\section{Data extraction and quality assessment}

Two authors independently extracted the data, which were recorded on a standard spreadsheet. Disagreements were resolved through discussions with two other researchers. To understand better the effects of the type or duration of treatment on eradication, we divided the treatments into 14 groups (table 1). Extracted data included the characteristics of the studies (title, publication year, country, and study design), characteristics of the patients (number of patients, age, number of men and women, assessment method for $H$ pylori infection, assessment method for $H$ pylori eradication, observation interval between end of treatment and time $H$ pylori eradication was confirmed), characteristics of the treatments (intervention, dosage, and duration), and outcomes (number of patients included in the intention to treat analysis, number of patients with successful eradication according to the intention to treat analysis, number of patients included in the analysis of adverse events, number of patients presenting with each of the most common adverse events). The primary outcome of this study was the efficacy of each eradication treatment, according to intention to treat analysis. The secondary outcome was the tolerance analysis, including the occurrence of adverse events in each eradication treatment. Two authors independently assessed the quality of evidence using both the Jadad scale $^{29}$ and the Cochrane Collaboration's tool for evaluating study bias. ${ }^{27} 30$

\section{Data synthesis and analysis}

We used the traditional pairwise meta-analysis method to analyse direct treatment comparisons. A random effects model, which provides more conservative estimated effects, was applied. As all results were extracted as binary outcomes, we calculated the summary effect sizes as relative risks, with $95 \%$ confidence intervals. The statistical heterogeneity among studies was assessed by the Cochran's Q test and the $\mathrm{I}^{2}$ statistic. ${ }^{31} \mathrm{~A}$ $P$ value of 0.10 or less for the $Q$ test or an $I^{2}$ greater than $50 \%$ was suggestive of substantial between study heterogeneity. Publication bias was tested using funnel plots. ${ }^{31}$

We analysed pooled data for all eradication treatments with random effects models, within a bayesian framework, using WinBUGS. ${ }^{32}$ Summary effect sizes were calculated as relative risks, with $95 \%$ credible intervals. ${ }^{32}$ To summarise the efficacy and tolerance of all treatments, we also calculated the absolute rates and relative ranks of different eradication treatments. ${ }^{32}$ The resultant rankings are presented graphically.

Meta-regression analyses were used by adding other covariates, such as mean or median age, Jadad scores, sex ratio, and observation intervals between the end of treatment and the time that $H$ pylori eradication was confirmed to the network meta-analysis model. ${ }^{33}$ Inconsistency of direct and indirect estimates was also analysed for the primary outcome. Differences between direct and indirect estimates were calculated using a loop specific method. ${ }^{34}$ Country specific subgroup network meta-analyses were performed based on different countries if five or more studies were available for a country.

Sensitivity analyses were adopted for the primary outcome according to several prespecified variables: publication year (including only studies published after 2000), risks of bias (excluding studies with more than one item indicating a high risk of bias assessed by the Cochrane risk of bias tool), and sample size (excluding studies in which any comparator group contained fewer than 50 participants).

For traditional meta-analyses we used Cochrane Collaboration review manager software and MetaAnalyst Beta 3.13. For network meta-analyses we used WinBUGS 1.4.3 and STATA 11.0.

\begin{tabular}{ll}
\hline $\begin{array}{l}\text { Table } 1 \text { | General characteristics of treatments for eradication of Helicobacter pylori } \\
\text { Treatment abbreviations }\end{array}$ & General characteristics \\
\hline 7 days triple & 7 days simultaneous PPI+3 antibiotics (often amoxicillin, clarithromycin and 5-nitroimidazole) \\
\hline 7 days concomitant & 5 or 7 days simultaneous PPI+amoxicillin, followed by 5 or 7 days simultaneous PPI+clarithromycin+(5-nitroimidazole or amoxicillin) \\
\hline 10 or 14 days sequential & 10 or 14 days simultaneous PPI+clarithromycin+(amoxicillin or metronidazole) \\
\hline 10 or 14 days triple & 10 or 14 days simultaneous PPI+bismuth compounds+2 antibiotics \\
\hline 10 or 14 days bismuth & 7 days simultaneous PPI+bismuth compounds+2 antibiotics \\
\hline 7 days bismuth & 10 or 14 days simultaneous PPI+3 antibiotics (often amoxicillin, clarithromycin, and 5-nitroimidazole) \\
\hline 10 or 14 days concomitant & 7 days standard triple treatment supplemented with probiotics \\
\hline 7 days probiotic & 10 or 14 days standard triple treatment supplemented with probiotics \\
\hline 10 or 14 days probiotic & 7 days simultaneous ranitidine bismuth citrate+any 2 of amoxicillin, clarithromycin, and metronidazole \\
\hline 7 days ranitidine bismuth & 10 or 14 days simultaneous ranitidine bismuth citrate+any 2 of amoxicillin, clarithromycin, and metronidazole \\
\hline 10 or 14 days ranitidine bismuth & 7 days simultaneous PPI+levofloxacin+1 antibiotic \\
\hline 7 days levofloxacin & 10 or 14 days simultaneous PPI+levofloxacin+1 antibiotic \\
\hline 10 or 14 days levofloxacin & 7 days simultaneous PPI+amoxicillin, followed by 7 days simultaneous PPI+amoxicillin+clarithromycin+5-nitroimidazole
\end{tabular}




\section{Results}

Study characteristics and quality assessment

Through literature searches, 15565 studies were identified, of which 15281 were excluded after screening of the titles and abstracts. The full texts of 284 remaining studies were reviewed. Overall, 143 studies were eligible and were included (see study inclusion flowchart in supplementary appendix 1, fig S1.1). These 143 studies covered 14 kinds of treatments (table 1). Of 91 possible comparisons between treatment regimens for the primary outcome, 34 were compared directly in the studies we identified. In total, 32056 patients contributed to the efficacy analysis and 22180 to the tolerance analysis. The average age of patients with $H$ pylori was 47 years, and approximately $53 \%$ of participants were men. The baseline characteristics of the included studies are listed in supplementary appendix 1, table S1.1, and the citation details are given in supplementary appendix 2 . The risk of bias summary and figure for included studies are listed in supplementary appendix 3. Some studies did not present details for randomisation, allocation concealment, and blinding.

\section{Treatment efficacy}

In total, the success of $H$ pylori eradication was assessed for 14 treatments, presented in 143 studies, and data were available for 32056 patients (intention to treat analysis). All commonly used treatments were assessed in at least one randomised controlled trial. Figure 1 graphically represents the network of eligible comparisons for the efficacy outcome of the network metaanalysis. For the efficacy outcome, the network meta-analysis estimations indicated that most treatments were better than the previously recommended seven days of standard triple treatment, the two exceptions being the seven days of levofloxacin based triple treatment and seven days of bismuth based quadruple

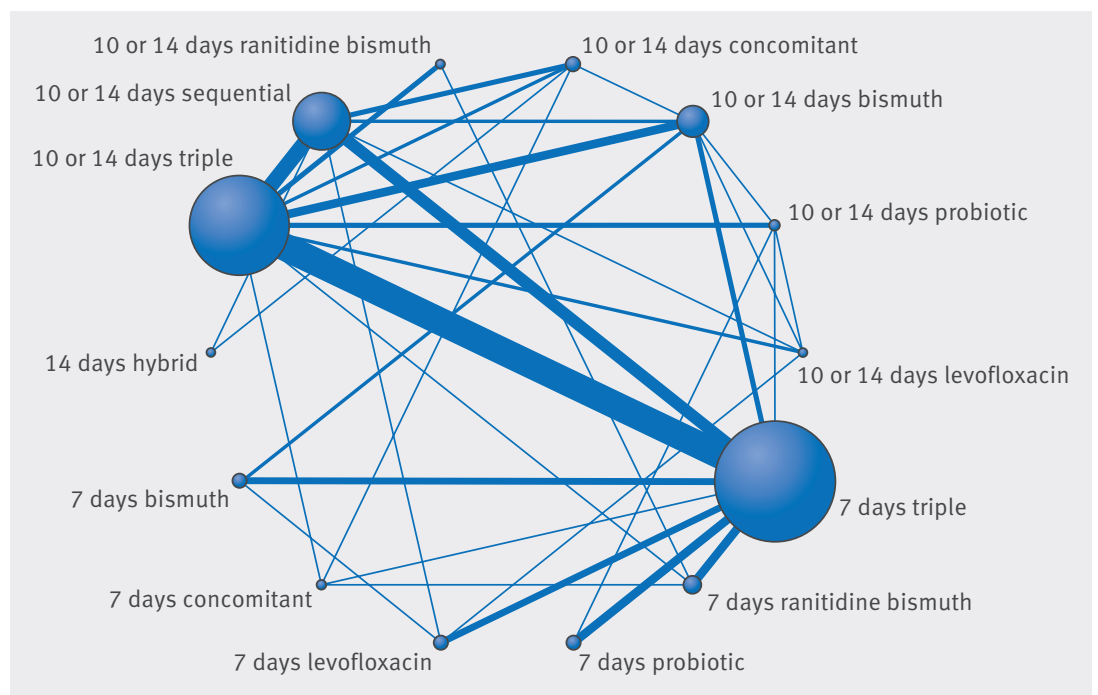

Fig 1 | Network of eligible comparisons for treatment efficacy network meta-analysis. The width of lines is proportional to the number of studies compared in every pair of treatments, and the size of nodes is proportional to the total sample size of each treatment treatment, which were comparable to the seven days of standard triple treatment (table 2 and fig 2). In the comparisons between seven days and 10 or 14 days of treatments, longer treatments in most cases were better, and this was the case for standard triple treatments, levofloxacin based triple treatments, probiotic supplemented triple treatments, and bismuth based quadruple treatments. For the concomitant treatments and ranitidine bismuth citrate based triple treatments, the efficacy of the shorter treatments was comparable to that of the longer treatments (see supplementary appendix 4, table S4.1).

In terms of eradication rates, all treatments, including the seven days of standard triple treatment, were still effective. Ranking on efficacy indicated that seven days of concomitant treatment was the highest, followed by 10 or 14 days of concomitant treatment, 10 or 14 days of probiotic supplemented triple treatment, 10 or 14 days of levofloxacin based triple treatment, 14 days of hybrid treatment, 10 or 14 days of sequential treatment, 10 or 14 days of ranitidine bismuth citrate based triple treatment, and 10 or 14 days of bismuth based quadruple treatment. Table 2 lists the eradicative effects of each treatment compared with the seven days of standard triple treatment and supplementary appendix 4, table S4.1 presents the results across all other treatment comparisons. Despite the seven days of concomitant treatment ranking the highest, data on this treatment method was provided by only three studies and in 504 participants.

Heterogeneity in pairwise meta-analysis was generally moderate (see supplementary appendix 4, table S4.2). Similarly, no statistically significant inconsistency was indicated in most loops within the network for the efficacy outcome.

\section{Tolerance of treatments \\ Treatment comparison for total occurrence of adverse events}

A total of 99 studies were included in the comparison of total occurrence rates of adverse events among the 14 treatments. Figure 3 graphically represents the network of eligible comparisons for the adverse event outcome of the network meta-analysis. Generally, the shorter the treatment time was, the lower the likelihood of adverse events. In our network meta-analysis comparisons, seven days of probiotic supplemented triple treatment and seven days of levofloxacin based triple treatment were significantly better than the seven days of standard triple treatment (table 3 and fig 4). These two treatments ranked the best in terms of tolerance. Risks of any adverse event ranged from $14-34 \%$ in the different treatments. However, the results should be interpreted with caution because most network meta-analysis comparisons between the various treatments did not reach statistical significance. Table 3 lists the comparisons of adverse events for each treatment with the seven days of standard triple treatment. All other comparisons are shown in supplementary appendix 5, table S5.1. The results of pairwise meta-analyses are also given in supplementary appendix 5, table S5.2. 
Table 2 | Efficacy of treatment for Helicobacter pylori eradication compared with seven days of standard triple treatment, eradication rates for all treatments, and treatment effectiveness rank

\begin{tabular}{|c|c|c|c|c|c|c|}
\hline \multirow[b]{2}{*}{ Treatments } & \multirow[b]{2}{*}{$\begin{array}{l}\text { No of studies } \\
\text { comparing with } \\
7 \text { days triple }\end{array}$} & \multirow[b]{2}{*}{$\begin{array}{l}\text { No of } \\
\text { participants }\end{array}$} & \multicolumn{2}{|l|}{ Intention to treat } & \multirow[b]{2}{*}{$\begin{array}{l}\text { Eradication rate } \\
(95 \% \mathrm{Crl})\end{array}$} & \multirow[b]{2}{*}{ Mean rank* $(95 \% \mathrm{Crl})$} \\
\hline & & & $\begin{array}{l}\text { Network } \\
\text { meta-analysis: } \\
\text { risk ratio }(95 \% \mathrm{Crl})\end{array}$ & $\begin{array}{l}\text { Direct } \\
\text { comparison: risk } \\
\text { ratio }(95 \% \mathrm{Cl})\end{array}$ & & \\
\hline 7 days triple & & & 1 & 1 & $0.73(0.71$ to 0.75$)$ & $13.77(13$ to 14$)$ \\
\hline 7 days concomitant & 1 & 119 & $1.29(1.22$ to 1.35$)$ & 1.39 (1.16 to 1.67$)$ & 0.94 (0.89 to 0.98) & $1.34(1$ to 4$)$ \\
\hline 10 or 14 days sequential & 15 & 3713 & 1.20 (1.16 to 1.23$)$ & $1.22(1.19$ to 1.27$)$ & 0.87 (0.85 to 0.90$)$ & $5.82(4$ to 8$)$ \\
\hline 10 or 14 days triple & 32 & 6844 & $1.12(1.08$ to 1.15$)$ & $1.08(1.05$ to 1.12$)$ & $0.81(0.78$ to 0.84$)$ & 10.37 (9 to 12$)$ \\
\hline 10 or 14 days bismuth & 6 & 1188 & $1.17(1.12$ to 1.21$)$ & 1.27 (1.04 to 1.55$)$ & 0.85 (0.82 to 0.89$)$ & $7.52(5$ to 10$)$ \\
\hline 7 days bismuth & 8 & 1340 & $1.08(1.00$ to 1.15$)$ & 1.07 (1.00 to 1.15$)$ & $0.79(0.73$ to 0.84$)$ & 11.52 (8 to 14$)$ \\
\hline 10 or 14 days concomitant & 0 & 0 & 1.24 (1.19 to 1.29$)$ & NA & 0.91 (0.87 to 0.94) & $3.23(1$ to 6$)$ \\
\hline 7 days probiotic & 11 & 2392 & 1.14 (1.07 to 1.20$)$ & $1.14(1.09$ to 1.19$)$ & $0.83(0.78$ to 0.87$)$ & $9.21(6$ to 12$)$ \\
\hline 10 or 14 days probiotic & 1 & 33 & 1.24 (1.17 to 1.29$)$ & 1.13 (0.69 to 1.84$)$ & $0.90(0.85$ to 0.94$)$ & 3.43 (1 to 7$)$ \\
\hline 7 days ranitidine bismuth & 11 & 1839 & $1.12(1.04$ to 1.18$)$ & $1.10(1.04$ to 1.16$)$ & $0.82(0.76$ to 0.86$)$ & 10.06 (7 to 13$)$ \\
\hline 10 or 14 days ranitidine bismuth & 0 & 0 & 1.17 (1.07 to 1.25$)$ & NA & 0.86 (0.78 to 0.91$)$ & 7.20 (3 to 12$)$ \\
\hline 7 days levofloxacin & 8 & 2329 & 1.04 (0.95 to 1.11$)$ & 1.01 (0.92 to 1.10$)$ & 0.76 (0.69 to 0.81$)$ & $12.86(11$ to 14$)$ \\
\hline 10 or 14 days levofloxacin & 0 & 0 & 1.23 (1.16 to 1.29$)$ & NA & $0.90(0.84$ to 0.94$)$ & 3.95 (1 to 8$)$ \\
\hline 14 days hybrid & 0 & 0 & $1.22(1.11$ to 1.29$)$ & NA & $0.89(0.81$ to 0.94$)$ & 4.71 (1 to 10$)$ \\
\hline
\end{tabular}

$\mathrm{Cr}=$ credible interval; $\mathrm{NA}=$ not applicable.

*Rank was derived from eradication rate values for all studies, $1=$ best efficacy.

Fig 2 | Forest plot of network meta-analysis results for treatment efficacy outcomes compared with seven days of standard triple treatment
Efficacy

7 days triple $v$

7 days concomitant 10 or 14 days sequential 10 or 14 days triple 10 or 14 days bismuth 7 days bismuth

10 or 14 days concomitant 7 days probiotic

10 or 14 days probiotic

7 days ranitidine bismuth

10 or 14 days ranitidine bismuth

7 days levofloxacin

10 or 14 days levofloxacin

14 days hybrid

\section{Risk ratio (95\% credible interval)}

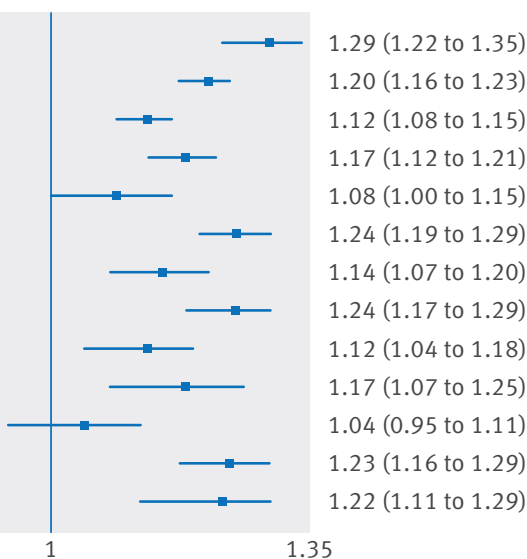

Fig $3 \mid$ Network of eligible comparisons for treatment tolerance network meta-analysis. The width of lines is proportional to the number of studies compared in every pair of treatments, and the size of nodes is proportional to the total sample size of each treatment

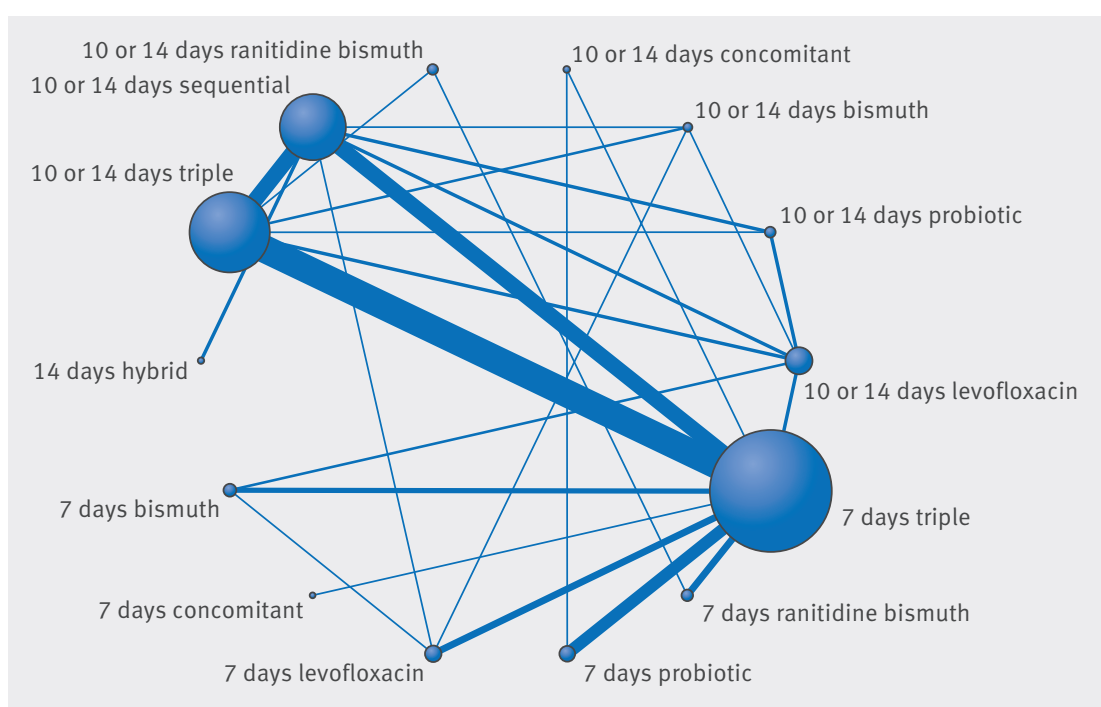




\begin{tabular}{|c|c|c|c|c|c|c|}
\hline \multirow[b]{2}{*}{ Treatments } & \multirow{2}{*}{$\begin{array}{l}\text { No of studies } \\
\text { comparing with } \\
7 \text { days triple }\end{array}$} & \multirow[b]{2}{*}{$\begin{array}{l}\text { No of } \\
\text { participants }\end{array}$} & \multicolumn{2}{|l|}{ Adverse events } & \multirow{2}{*}{$\begin{array}{l}\text { Mean occurrence } \\
\text { of adverse events } \\
(95 \% \mathrm{Crl})\end{array}$} & \multirow[b]{2}{*}{$\begin{array}{l}\text { Mean rank* } \\
(95 \% \mathrm{Crl})\end{array}$} \\
\hline & & & $\begin{array}{l}\text { Network meta-analysis: } \\
\text { risk ratio }(95 \% \mathrm{Crl})\end{array}$ & $\begin{array}{l}\text { Direct comparison: } \\
\text { risk ratio }(95 \% \mathrm{CI})\end{array}$ & & \\
\hline 7 days triple & & & 1 & 1 & $0.21(0.18$ to 0.26$)$ & 6.41 (3 to 10$)$ \\
\hline 7 days concomitant & 1 & 110 & 1.19 (0.49 to 2.20) & 1.10 (0.70 to 1.73$)$ & 0.26 (0.10 to 0.48$)$ & 8.58 (1 to 14$)$ \\
\hline 10 or 14 days sequential & 13 & 3216 & $1.00(0.85$ to 1.18$)$ & 0.99 (0.83 to 1.19) & $0.22(0.17$ to 0.27$)$ & $6.42(3$ to 10$)$ \\
\hline 10 or 14 days triple & 22 & 4560 & $1.10(0.94$ to 1.26$)$ & 1.14 (1.01 to 1.28$)$ & 0.24 (0.18 to 0.29$)$ & 8.94 (5 to 12$)$ \\
\hline 10 or 14 days bismuth & 4 & 970 & $1.08(0.85$ to 1.34$)$ & $0.86(0.74$ to 1.01$)$ & 0.23 (0.17 to 0.30$)$ & 8.33 (4 to 13$)$ \\
\hline 7 days bismuth & 5 & 764 & 0.97 (0.69 to 1.32) & $1.04(0.94$ to 1.16$)$ & 0.21 (0.14 to 0.30$)$ & 6.14 (2 to 13) \\
\hline 10 or 14 days concomitant & 0 & 0 & 1.13 (0.83 to 1.48$)$ & NA & 0.24 (0.17 to 0.33) & 9.19 (3 to 13) \\
\hline 7 days probiotic & 9 & 2158 & 0.65 (0.47 to 0.87$)$ & $0.72(0.49$ to 1.06$)$ & 0.14 (0.09 to 0.20$)$ & $1.72(1$ to 4$)$ \\
\hline 10 or 14 days probiotic & 1 & 30 & 1.59 (0.44 to 3.18) & 1.25 (0.41 to 3.77$)$ & $0.34(0.09$ to 0.68$)$ & $10.67(1$ to 14$)$ \\
\hline 7 days ranitidine bismuth & 6 & 943 & $1.16(0.81$ to 1.59$)$ & 1.29 (1.06 to 1.56$)$ & 0.25 (0.16 to 0.35$)$ & $9.53(3$ to 14$)$ \\
\hline 10 or 14 days ranitidine bismuth & 0 & 0 & 0.99 (0.64 to 1.42$)$ & NA & 0.21 (0.13 to 0.32$)$ & 6.44 (2 to 13$)$ \\
\hline 7 days levofloxacin & 6 & 1413 & $0.69(0.49$ to 0.94$)$ & $0.72(0.54$ to 0.95$)$ & 0.15 (0.10 to 0.21$)$ & 2.09 (1 to 5) \\
\hline 10 or 14 days levofloxacin & 0 & 0 & 1.26 (0.83 to 1.79$)$ & NA & 0.27 (0.17 to 0.39) & 10.71 (3 to 14$)$ \\
\hline 14 days hybrid & 0 & 0 & $1.22(0.72$ to 1.86$)$ & NA & $0.26(0.15$ to 0.41$)$ & $9.83(2$ to 14$)$ \\
\hline
\end{tabular}

$\mathrm{Crl}=$ credible interval; $\mathrm{NA}=$ not applicable.

*Rank was derived from occurrence rate of adverse event values for all studies, $1=$ best tolerance.

\section{Treatment comparison for occurrence of adverse event subtypes}

In terms of the number of patients presenting with epigastric or abdominal pain, occurrence rates in the network meta-analysis revealed that ranitidine bismuth citrate based triple treatments and 10 or 14 days of probiotic supplemented triple treatment might be relatively optimal choices (table 4). The lowest rates of taste alteration were reported with seven days of levofloxacin based triple treatment and bismuth based quadruple treatments. Headaches with or without vomiting were experienced less frequently during probiotic supplemented triple treatments and 10 or 14 days of levofloxacin treatment. Patients taking the probiotic supplemented triple treatments and seven days of levofloxacin based triple treatment reported experiencing diarrhoea less often. Again, findings should be interpreted with caution since most comparisons did not reach statistical significance (see supplementary

Adverse events
7 days triple $v$
7 days concomitant
10 or 14 days sequential
10 or 14 days triple
10 or 14 days bismuth
7 days bismuth
10 or 14 days concomitant
7 days probiotic
10 or 14 days probiotic
7 days ranitidine bismuth
10 or 14 days ranitidine bismuth
7 days levofloxacin
10 or 14 days levofloxacin
14 days hybrid

0.314

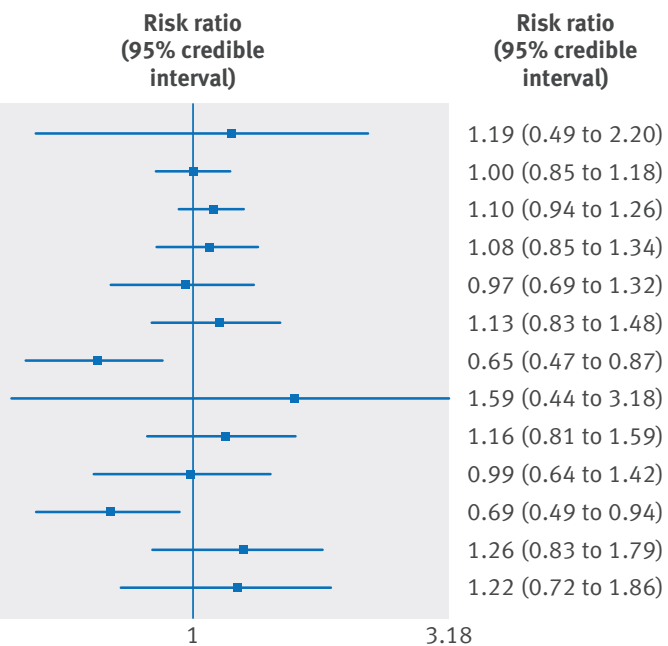

Fig 4 | Forest plot of network meta-analysis results for treatment tolerance outcomes compared with seven days of standard triple treatment appendix 5, tables S5.3, S5.5, S5.7, and S5.9). Credible intervals were not narrow in network meta-analysis comparisons and confidence intervals were wide in pairwise meta-analysis comparisons, reflecting the small number of studies available for these comparisons.

It was impossible to subdivide treatment groups further owing to the limited number of studies for each subgroup. However, we recognise that adverse events, particularly taste alteration, may differ by antibiotic choice. Clarithromycin may be one of the main contributors to risk of experiencing taste alteration: seven days of levofloxacin based triple treatment (proton pump inhibitor, levofloxacin, and amoxicillin) was compared with seven days of standard triple treatment (proton pump inhibitor, clarithromycin, and amoxicillin), and a lower risk for taste alteration was seen with levofloxacin instead of clarithromycin (data not shown).

Table 4 shows the occurrence rates and the relative ranks of treatments in terms of subtypes of adverse events. Supplementary appendix 5, tables S5.3-S5.10 list all the results of network meta-analysis and pairwise meta-analysis.

\section{Effectiveness versus harms}

Figure 5 presents all eradication treatments ordered by their relative ranks for efficacy, showing the separate contributions to the overall results of efficacy and tolerance. We found that 7, 10, or 14 days of concomitant treatment, 10 or 14 days of probiotic supplemented triple treatment, 10 or 14 days of levofloxacin based triple treatment, 14 days of hybrid treatment, and 10 or 14 days of sequential treatment were among the most effective treatments, whereas seven days of probiotic supplemented triple treatment and seven days of levofloxacin based triple treatment performed better in the tolerance analysis. In figure 6, we ranked these eradication treatments according to both dimensions of efficacy and tolerance. Longer treatments in most cases were better for the efficacy outcomes and worse for adverse events, as most of these treatments lay in the upper left corner, 


\begin{tabular}{|c|c|c|c|c|c|c|c|c|}
\hline \multirow[b]{2}{*}{ Treatments } & \multicolumn{2}{|c|}{ Abdominal or epigastric pain } & \multicolumn{2}{|l|}{ Alteration in taste } & \multicolumn{2}{|c|}{ Headache with or without vomiting } & \multicolumn{2}{|l|}{ Diarrhoea } \\
\hline & $\begin{array}{l}\text { Mean occurrence } \\
\text { rate }(95 \% \mathrm{Crl})\end{array}$ & $\begin{array}{l}\text { Mean rank* } \\
(95 \% \mathrm{Crl})\end{array}$ & $\begin{array}{l}\text { Mean occurrence } \\
\text { rate }(95 \% \mathrm{Crl})\end{array}$ & $\begin{array}{l}\text { Mean rank* } \\
(95 \% \mathrm{Crl})\end{array}$ & $\begin{array}{l}\text { Mean occurrence } \\
\text { rate }(95 \% \mathrm{Crl})\end{array}$ & $\begin{array}{l}\text { Mean rank* } \\
(95 \% \mathrm{Crl})\end{array}$ & $\begin{array}{l}\text { Mean occurrence } \\
\text { rate }(95 \% \mathrm{Crl})\end{array}$ & $\begin{array}{l}\text { Mean rank* } \\
(95 \% \mathrm{Crl})\end{array}$ \\
\hline 7 days triple & 0.05 (0.03 to 0.07$)$ & 8.84 (7 to 12$)$ & 0.08 (0.06 to 0.11$)$ & 7.16 (5 to 10$)$ & $0.03(0.02$ to 0.04$)$ & 5.67 (3 to 8 ) & 0.08 (0.07 to 0.10$)$ & 9.07 (6 to 12$)$ \\
\hline 7 days concomitant & 0.14 (0.03 to 0.39$)$ & 13.01 (6 to 14$)$ & 0.30 (0.06 to 0.74$)$ & 13.01 (5 to 14$)$ & NA & NA & 0.12 (0.04 to 0.27$)$ & $10.96(3$ to 14$)$ \\
\hline $\begin{array}{l}10 \text { or } 14 \text { days } \\
\text { sequential }\end{array}$ & 0.05 (0.03 to 0.08$)$ & 9.45 (7 to 12$)$ & 0.09 (0.05 to 0.14$)$ & $8.29(5$ to 11$)$ & 0.05 (0.02 to 0.10$)$ & $9.22(6$ to 12$)$ & 0.07 (0.04 to 0.09$)$ & $5.62(3$ to 9$)$ \\
\hline 10 or 14 days triple & 0.06 (0.03 to 0.09$)$ & 10.93 (8 to 13$)$ & $0.12(0.07$ to 0.18$)$ & 11.22 (9 to 13$)$ & 0.04 (0.02 to 0.08$)$ & $7.98(5$ to 11$)$ & 0.09 (0.06 to 0.12$)$ & 9.34 (6 to 12$)$ \\
\hline 10 or 14 days bismuth & 0.06 (0.04 to 0.10$)$ & $11.77(8$ to 14$)$ & 0.05 (0.02 to 0.08$)$ & $2.40(1$ to 5$)$ & 0.08 (0.03 to 0.17$)$ & 11.51 (9 to 13$)$ & 0.07 (0.04 to 0.12$)$ & 7.11 (3 to 13$)$ \\
\hline 7 days bismuth & 0.06 (0.03 to 0.11$)$ & 10.99 (6 to 14$)$ & 0.05 (0.03 to 0.09$)$ & 3.56 (1 to 8$)$ & 0.05 (0.02 to 0.11$)$ & 9.46 (5 to 13$)$ & 0.11 (0.07 to 0.18$)$ & 11.88 (6 to 14$)$ \\
\hline $\begin{array}{l}10 \text { or } 14 \text { days } \\
\text { concomitant }\end{array}$ & 0.06 (0.03 to 0.10$)$ & 10.31 (6 to 14$)$ & $0.10(0.05$ to 0.17$)$ & 8.91 (4 to 13$)$ & $0.06(0.02$ to 0.16$)$ & 9.62 (4 to 13$)$ & $0.09(0.05$ to 0.14$)$ & $9.29(4$ to 14$)$ \\
\hline 7 days probiotic & $0.03(0.02$ to 0.05$)$ & 5.85 (4 to 10$)$ & 0.07 (0.04 to 0.12$)$ & $6.02(3$ to 11$)$ & 0.01 (0.00 to 0.06$)$ & 3.15 (1 to 10$)$ & 0.05 (0.03 to 0.08$)$ & 3.36 (1 to 7$)$ \\
\hline $\begin{array}{l}10 \text { or } 14 \text { days } \\
\text { probiotic }\end{array}$ & 0.02 (0.01 to 0.03$)$ & 3.41 (1 to 6$)$ & 0.17 (0.08 to 0.31$)$ & 12.72 (9 to 14$)$ & 0.01 (0.00 to 0.03 ) & $1.82(1$ to 6$)$ & 0.03 (0.01 to 0.05$)$ & 1.29 (1 to 3$)$ \\
\hline $\begin{array}{l}7 \text { days ranitidine } \\
\text { bismuth }\end{array}$ & 0.01 (0.00 to 0.04$)$ & 1.91 (1 to 6$)$ & 0.08 (0.04 to 0.13$)$ & 6.11 (2 to 12) & 0.07 (0.00 to 0.33$)$ & 7.47 (1 to 13$)$ & 0.09 (0.04 to 0.17$)$ & 9.59 (3 to 14) \\
\hline $\begin{array}{l}10 \text { or } 14 \text { days } \\
\text { ranitidine bismuth }\end{array}$ & 0.01 (0.00 to 0.03$)$ & 1.94 (1 to 5$)$ & 0.09 (0.04 to 0.17$)$ & 8.28 (3 to 13$)$ & 0.02 (0.00 to 0.09$)$ & $4.68(1$ to 11$)$ & 0.07 (0.03 to 0.12$)$ & 6.18 (2 to 13$)$ \\
\hline 7 days levofloxacin & 0.04 (0.02 to 0.07$)$ & 7.11 (4 to 12 ) & 0.04 (0.02 to 0.06$)$ & 1.68 (1 to 4$)$ & 0.03 (0.01 to 0.06$)$ & $5.96(2$ to 11$)$ & 0.05 (0.03 to 0.08$)$ & 3.47 (1 to 8$)$ \\
\hline $\begin{array}{l}10 \text { or } 14 \text { days } \\
\text { levofloxacin }\end{array}$ & 0.03 (0.01 to 0.06$)$ & 4.97 (2 to 11$)$ & 0.07 (0.03 to 0.14$)$ & 4.91 (1 to 11$)$ & 0.02 (0.00 to 0.06$)$ & 3.73 (1 to 9) & 0.11 (0.05 to 0.19$)$ & $11.17(5$ to 14$)$ \\
\hline 14 days hybrid & 0.02 (0.01 to 0.06$)$ & $4.52(1$ to 11$)$ & $0.13(0.05$ to 0.24$)$ & 10.74 (4 to 14$)$ & 0.20 (0.01 to 0.86$)$ & 10.73 (2 to 13$)$ & 0.08 (0.02 to 0.19$)$ & 6.68 (1 to 14) \\
\hline
\end{tabular}

$\mathrm{Crl}=$ credible interval; $\mathrm{NA}=$ not applicable.

*Rank was derived from occurrence rate of values for adverse event subtypes for all studies, $1=$ best tolerance.

whereas shorter treatments tended to have more optimal tolerance outcomes but lower efficacy as they appear mostly in the lower right corner of the figure.

\section{Network assumptions, sensitivity analysis, and publication bias}

The meta-regression with efficacy outcomes indicated that mean or median age, sex ratio, Jadad score, and observation interval between the end of treatment and the time $H$ pylori eradication was confirmed did not lead to significant changes in the results.

Sensitivity analyses of the publication year and the risks of bias of the included studies did not show any major change in the primary outcome (see supplementary appendix 4, table S4.1). However, if we excluded studies in which any comparison group had a sample

\begin{tabular}{|c|c|c|c|c|c|c|c|c|c|c|c|c|c|}
\hline concomitant & $\begin{array}{c}0.91 \\
.39 \text { to } 1.98)\end{array}$ & $\begin{array}{c}0.64 \\
.14 \text { to } 1.74)\end{array}$ & \begin{tabular}{|c}
0.81 \\
(0.33 to 1.81 )
\end{tabular} & $\begin{array}{c}0.84 \\
.32 \text { to } 1.92)\end{array}$ & $\begin{array}{c}1.02 \\
.47 \text { to } 2.18 \text { ) }\end{array}$ & $\begin{array}{c}1.03 \\
\text { (0.42 to } 2.31 \text { ) }\end{array}$ & $\begin{array}{c}0.95 \\
0.42 \text { to } 2.05 \text { ) }\end{array}$ & $\begin{array}{c}1.57 \\
\text { (0.67 to } 3.44 \text { ) }\end{array}$ & $\begin{array}{c}0.88 \\
\text { (0.37 to } 1.93)\end{array}$ & $\begin{array}{c}0.94 \\
\text { (0.43 to } 1.99)\end{array}$ & $\begin{array}{c}1.05 \\
\text { (0.45 to } 2.31 \text { ) }\end{array}$ & $\begin{array}{c}1.48 \\
\text { (0.63 to } 3.25 \text { ) }\end{array}$ & $\begin{array}{c}1.19 \\
\text { (0.49 to } 2.20 \text { ) }\end{array}$ \\
\hline $99 t$ & & 19 to & $.54 \mathrm{tc}$ & $51 \mathrm{t}$ & 85 tc & $68 \mathrm{t}$ & 76 tc & $\begin{array}{r}1 . \\
(1.08 \mathrm{t}\end{array}$ & $\begin{array}{r}0 . \\
.59 \mathrm{t}\end{array}$ & $.76 \mathrm{t}$ & 8) & $\begin{array}{r}1 \\
01 t\end{array}$ & 1.48) \\
\hline (0.98 to 1.12 ) & $\begin{array}{c}1.00 \\
.94 \text { to } 1.06)\end{array}$ & probiotic & $\begin{array}{c}0.96 \\
\text { (0.32 to } 2.74)\end{array}$ & $\begin{array}{c}1.00 \\
.31 \text { to } 2.87 \text { ) }\end{array}$ & .44 to 3.26 ) & $\begin{array}{c}1.23 \\
0.41 \text { to } 3.52 \text { ) }\end{array}$ & $\begin{array}{c}1.49 \\
.41 \text { to } 3.09 \text { ) }\end{array}$ & $\begin{array}{c}2.48 \\
\text { (0.69 to } 5.11)\end{array}$ & $\begin{array}{c}1.05 \\
0.36 \text { to } 2.96 \text { ) }\end{array}$ & 0.40 to 2.97 ) & $\begin{array}{c}1.68 \\
\text { (0.44 to } 3.58)\end{array}$ & $\begin{array}{c}1.76 \\
\text { (0.61 to } 4.97 \text { ) }\end{array}$ & $\begin{array}{c}1.59 \\
\text { (0.44 to } 3.18 \text { ) }\end{array}$ \\
\hline$(0.99 \mathrm{t}$ & $\begin{array}{r}1.0 \\
.95 \text { to }\end{array}$ & $\begin{array}{r}1.0 \\
94 \text { to }\end{array}$ & & $\begin{array}{c}1.00 \\
.52 \text { to } 1.71)\end{array}$ & $\begin{array}{r}1.2 \\
.83 \text { to }\end{array}$ & $\begin{array}{r}1.3 \\
.75 \text { tc }\end{array}$ & $\begin{array}{c}1.18 \\
.75 \text { to } 1.72 \text { ) }\end{array}$ & $(1.17 \mathrm{tc}$ & $\begin{array}{r}1.1 \\
.64 \mathrm{tc}\end{array}$ & $.77 \mathrm{tc}$ & $.78 \mathrm{t}$ & $.11 \mathrm{t}$ & $(0.83 t$ \\
\hline $\begin{array}{c}1.06 \\
\text { (0.96 to } 1.15)\end{array}$ & $\begin{array}{c}1.02 \\
.93 \text { to } 1.09 \text { ) }\end{array}$ & $\begin{array}{c}1.02 \\
.92 \text { to } 1.10 \text { ) }\end{array}$ & $\begin{array}{l}1.01 \\
91 \text { to } 1.10 \text { ) }\end{array}$ & id & $\begin{array}{c}1.22 \\
74 \text { to } 1.82)\end{array}$ & $\begin{array}{r}1.2 \\
.66 \text { to }\end{array}$ & $\begin{array}{c}1.15 \\
.65 \text { to } 1.80 \text { ) }\end{array}$ & $\begin{array}{r}1.5 \\
.03 \mathrm{t}\end{array}$ & $\begin{array}{r}1.0 \\
.57 \mathrm{tc}\end{array}$ & 1.71) & $\begin{array}{r}1 \\
.68\end{array}$ & $\begin{array}{r}1 \\
.96\end{array}$ & 1.86) \\
\hline $\begin{array}{c}1.08 \\
\text { (1.03 to } 1.1\end{array}$ & $\begin{array}{c}1.04 \\
.99 \text { to } 1.07)\end{array}$ & $\begin{array}{c}1.03 \\
.98 \text { to } 1.08)\end{array}$ & $\begin{array}{c}1.03 \\
.97 \text { to } 1.08\end{array}$ & $\begin{array}{c}1.02 \\
.93 \text { to } 1 .\end{array}$ & seque & $\begin{array}{c}1.01 \\
\text { (0.65 to } 1.4\end{array}$ & $\begin{array}{c}0.93 \\
.73 \text { to } 1.16)\end{array}$ & $\begin{array}{r}1.5 \\
(1.05 \text { to }\end{array}$ & $\begin{array}{r}0.8 \\
0.57 \mathrm{tt}\end{array}$ & $\begin{array}{r}0.9 \\
0.77 \mathrm{tc}\end{array}$ & $\begin{array}{c}1.02 \\
\text { (0.70 to } 1.43)\end{array}$ & $\begin{array}{c}1.44 \\
0.99 \text { to } 2.01\end{array}$ & $\begin{array}{c}1.00 \\
\text { (0.85 to } 1.18 \text { ) }\end{array}$ \\
\hline $\begin{array}{c}1.10 \\
(1.00 \text { to } 1.20)\end{array}$ & $\begin{array}{c}1.06 \\
.97 \text { to } 1.14)\end{array}$ & $\begin{array}{l}1.06 \\
96 \text { to } 1.14)\end{array}$ & $\begin{array}{c}1.05 \\
.96 \text { to } 1.15)\end{array}$ & $\begin{array}{c}1.04 \\
.93 \text { to } 1.1\end{array}$ & $\begin{array}{c}1.02 \\
.94 \text { to } 1.0\end{array}$ & \begin{tabular}{|c|}
10 or \\
ranit \\
bisn \\
\end{tabular} & $\begin{array}{c}0.93 \\
.58 \text { to } 1.38)\end{array}$ & $\begin{array}{r}1.5 \\
.91 \text { to }\end{array}$ & $\begin{array}{c}0.87 \\
(0.52 \text { to } 1.37)\end{array}$ & $\begin{array}{c}0.90 \\
(0.60 \text { to } 1.27)\end{array}$ & $\begin{array}{c}1.04 \\
\text { (0.60 to } 1.67)\end{array}$ & $\begin{array}{c}1.37 \\
.80 \text { to } 2.23 \text { ) }\end{array}$ & \begin{tabular}{|c|}
0.99 \\
(0.64 to 1.42 ) \\
\end{tabular} \\
\hline $\begin{array}{c}1.11 \\
\text { (1.05 to } 1.18)\end{array}$ & $\begin{array}{c}1.06 \\
.01 \text { to } 1.11)\end{array}$ & $\begin{array}{c}1.06 \\
.00 \text { to } 1.12 \text { ) }\end{array}$ & $\begin{array}{l}1.05 \\
.99 \text { to } 1.11)\end{array}$ & $\begin{array}{c}1.04 \\
.95 \text { to } 1.11)\end{array}$ & $\begin{array}{l}1.02 \\
.98 \text { to } 1.06)\end{array}$ & $\begin{array}{r}1.0 \\
(0.92 \text { tc }\end{array}$ & $\begin{array}{l}10 \text { or } 14 \text { days } \\
\text { bismuth }\end{array}$ & $\begin{array}{c}1.64 \\
\text { (1.09 to } 2.34)\end{array}$ & $\begin{array}{c}0.91 \\
\text { (0.59 to } 1.33 \text { ) }\end{array}$ & $\begin{array}{c}0.99 \\
\text { (0.78 to } 1.23 \text { ) }\end{array}$ & $\begin{array}{c}1.10 \\
\text { (0.75 to } 1.53)\end{array}$ & $\begin{array}{c}1.54 \\
\text { (1.02 to } 2.22)\end{array}$ & $\begin{array}{c}1.08 \\
\text { (0.85 to } 1.34 \text { ) }\end{array}$ \\
\hline $\begin{array}{c}1.14 \\
\text { (1.05 to } 1.23)\end{array}$ & $\begin{array}{c}1.09 \\
1.02 \text { to } 1.17)\end{array}$ & $\begin{array}{c}1.09 \\
01 \text { to } 1.18)\end{array}$ & $\begin{array}{c}1.08 \\
\text { (1.00 to } 1.17)\end{array}$ & $\begin{array}{c}1.07 \\
.97 \text { to } 1.17)\end{array}$ & $\begin{array}{l}1.06 \\
.99 \text { to } 1.12 \text { ) }\end{array}$ & $\begin{array}{r}1.0 \\
(0.93 \text { tc }\end{array}$ & $\begin{array}{l}1.03 \\
.96 \text { to } 1.10 \text { ) }\end{array}$ & $\begin{array}{r}7 \mathrm{~d} d \\
\text { prob }\end{array}$ & (0.33 to 0.84 ) & $\begin{array}{c}0.60 \\
\text { (0.41 to } 0.82)\end{array}$ & $\begin{array}{r}0.6 \\
(0.42 \mathrm{tc}\end{array}$ & $\begin{array}{r}0.92 \\
(0.57 \text { to }\end{array}$ & ( 0.47 to 0.87 ) \\
\hline $\begin{array}{c}1.16 \\
(1.07 \text { to } 1.25) \\
\end{array}$ & $\begin{array}{c}1.11 \\
.03 \text { to } 1.19)\end{array}$ & $\begin{array}{c}1.11 \\
02 \text { to } 1.20)\end{array}$ & \begin{tabular}{|c|}
1.10 \\
(1.01 to 1.20$)$ \\
\end{tabular} & $\begin{array}{c}1.09 \\
.98 \text { to } 1.19) \\
\end{array}$ & $\begin{array}{c}1.07 \\
.00 \text { to } 1.14)\end{array}$ & \begin{tabular}{|c|}
1.05 \\
(0.95 to 1.15 ) \\
\end{tabular} & $\begin{array}{c}1.05 \\
0.97 \text { to } 1.12) \\
\end{array}$ & $\begin{array}{c}1.01 \\
\text { (0.93 to } 1.10) \\
\end{array}$ & $\begin{array}{r}7 \\
\text { rani } \\
\text { bis } \\
\end{array}$ & $\begin{array}{c}1.07 \\
(0.72 \text { to } 1.49) \\
\end{array}$ & $\begin{array}{c}1.23 \\
\text { (0.74 to } 1.90)\end{array}$ & $\begin{array}{c}1.63 \\
(1.00 \text { to } 2.55)\end{array}$ & $\begin{array}{c}1.16 \\
\text { (0.81 to } 1.59 \text { ) }\end{array}$ \\
\hline $\begin{array}{c}1.16 \\
\text { (1.10 to } 1.24)\end{array}$ & $\begin{array}{c}1.11 \\
.07 \text { to } 1.16)\end{array}$ & $\begin{array}{c}1.11 \\
.05 \text { to } 1.16)\end{array}$ & $\begin{array}{c}1.10 \\
(1.14 \text { to } 1.16) \\
\end{array}$ & $\begin{array}{c}1.09 \\
1.00 \text { to } 1.16)\end{array}$ & $\begin{array}{c}1.07 \\
.04 \text { to } 1.11)\end{array}$ & $\begin{array}{c}1.05 \\
\text { (0.97 to } 1.12 \text { ) }\end{array}$ & $\begin{array}{c}1.05 \\
.01 \text { to } 1.09)\end{array}$ & $\begin{array}{c}1.02 \\
\text { (0.95 to } 1.08)\end{array}$ & $\begin{array}{c}1.00 \\
\text { (0.93 to } 1.07)\end{array}$ & $\begin{array}{l}\text { or } 14 \text { days } \\
\text { triple }\end{array}$ & $\begin{array}{c}1.12 \\
\text { (0.77 to } 1.55)\end{array}$ & $\begin{array}{c}1.58 \\
\text { (1.08 to } 2.19) \\
\end{array}$ & $\begin{array}{c}1.10 \\
\text { (0.94 to } 1.26)\end{array}$ \\
\hline $\begin{array}{c}1.20 \\
\text { (1.09 to } 1.30)\end{array}$ & $\begin{array}{c}1.15 \\
.06 \text { to } 1.25)\end{array}$ & $\begin{array}{c}1.15 \\
\text { (1.05 to } 1.26)\end{array}$ & \begin{tabular}{|c}
1.14 \\
(1.04 to 1.25$)$
\end{tabular} & $\begin{array}{c}1.13 \\
\text { (1.01 to } 1.25)\end{array}$ & $\begin{array}{c}1.11 \\
.02 \text { to } 1.19)\end{array}$ & $\begin{array}{c}1.09 \\
\text { (0.97 to } 1.20 \text { ) }\end{array}$ & $\begin{array}{c}1.08 \\
\text { (0.99 to } 1.16) \\
\end{array}$ & $\begin{array}{c}1.05 \\
\text { (0.96 to } 1.16)\end{array}$ & (0.94 to 1.14 ) & $\begin{array}{c}1.03 \\
\text { (0.95 to } 1.11)\end{array}$ & $\begin{array}{r}7 \mathrm{da} \\
\text { bism }\end{array}$ & $\begin{array}{c}1.37 \\
\text { (0.86 to } 2.08 \text { ) }\end{array}$ & $\begin{array}{c}0.97 \\
\text { (0.69 to } 1.32 \text { ) }\end{array}$ \\
\hline $\begin{array}{c}1.25 \\
\text { (1.13 to } 1.37)\end{array}$ & $\begin{array}{c}1.20 \\
.09 \text { to } 1.30)\end{array}$ & $\begin{array}{c}1.20 \\
.09 \text { to } 1.30)\end{array}$ & $\begin{array}{c}1.19 \\
\text { (1.09 to } 1.31)\end{array}$ & $\begin{array}{c}1.18 \\
\text { (1.05 to } 1.31)\end{array}$ & $\begin{array}{c}1.16 \\
\text { (1.06 to } 1.25)\end{array}$ & $\begin{array}{c}1.13 \\
\text { (1.01 to } 1.26)\end{array}$ & $\begin{array}{c}1.13 \\
(1.03 \text { to } 1.22)\end{array}$ & $\begin{array}{c}1.10 \\
\text { (0.99 to } 1.20)\end{array}$ & $\begin{array}{c}1.08 \\
(0.97 \text { to } 1.19)\end{array}$ & $\begin{array}{c}1.08 \\
\text { (0.98 to } 1.16)\end{array}$ & $\begin{array}{r}1 . \\
(0.94 t\end{array}$ & $\begin{array}{r}7 d \\
\text { levoflc }\end{array}$ & $\begin{array}{c}0.69 \\
\text { (0.49 to } 0.94)\end{array}$ \\
\hline $\begin{array}{c}1.29 \\
(1.22 \text { to } 1.35)\end{array}$ & $\begin{array}{c}1.24 \\
(1.19 \text { to } 1.29)\end{array}$ & $\begin{array}{c}1.24 \\
(1.17 \text { to } 1.29)\end{array}$ & $\begin{array}{c}1.23 \\
(1.16 \text { to } 1.29)\end{array}$ & $\begin{array}{c}1.22 \\
1.11 \text { to } 1.29)\end{array}$ & $\begin{array}{c}1.20 \\
.16 \text { to } 1.23)\end{array}$ & $\begin{array}{c}1.17 \\
\text { (1.07 to } 1.25)\end{array}$ & $\begin{array}{c}1.17 \\
(1.12 \text { to } 1.21)\end{array}$ & $\begin{array}{c}1.14 \\
\text { (1.07 to } 1.20)\end{array}$ & (1.04 to 1.18 ) & $\begin{array}{c}1.12 \\
\text { (1.08 to } 1.15)\end{array}$ & $\begin{array}{c}1.08 \\
\text { (1.00 to } 1.15)\end{array}$ & $\begin{array}{c}1.04 \\
\text { (0.95 to } 1.11)\end{array}$ & $\begin{array}{l}7 \text { days } \\
\text { triple }\end{array}$ \\
\hline
\end{tabular}

$\square$ Treatment $\square$ Efficacy (risk ratio 95\% credible interval)

$\square$ Occurrence of adverse events (risk ratio 95\% credible interval)

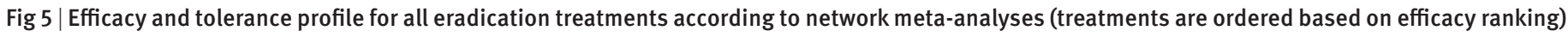




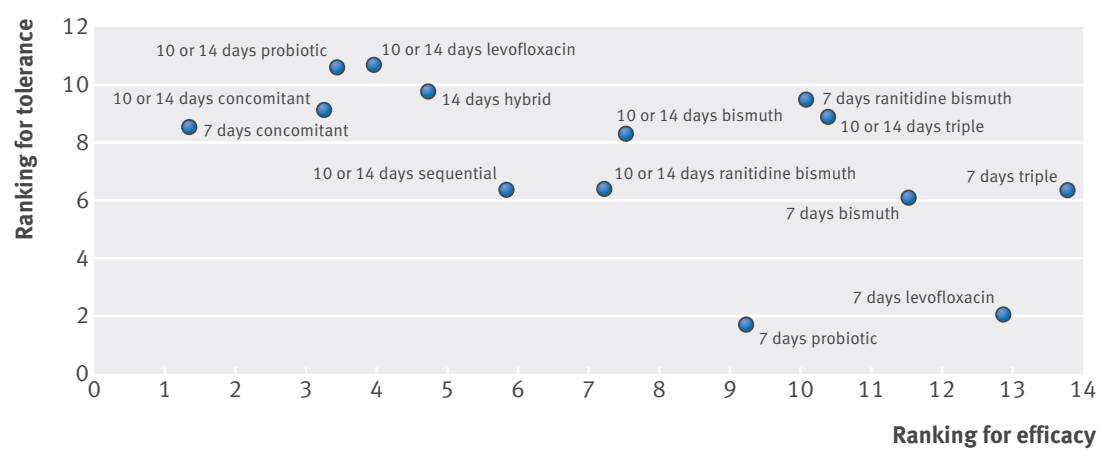

Fig 6 | Ranking for effectiveness and tolerance of Helicobacter pylori treatments in network meta-analyses based quadruple treatment, ${ }^{36}$ and sequential treatment. ${ }^{637}$ Seven days of standard triple treatment was consistently ranked last in our network meta-analysis. The most likely reason is growing resistance of Helicobacter pylori to clarithromycin and metronidazole. ${ }^{5}$ However, antibiotic resistance rates and thus efficacy will differ by region. One randomised controlled trial conducted in the United Kingdom ${ }^{38}$ and one in Hong Kong ${ }^{39}$ reported desirable eradication rates of over $90 \%$ with seven days of standard triple treatment. For those studies the resistance to clarithromycin was lower than $10 \%$. In contrast, an extremely low eradication rate of $44.4 \%$ was reported in Turkey where the resistance rate to clarithromycin is reported to be over $40 \% .{ }^{40}$ Therefore our analysis and other studies support the use of this standard triple treatment only in areas where clarithromycin resistance is lower than $15-20 \% .{ }^{541}$

Other than comparisons with seven days of standard triple treatment, the number of studies that analysed each particular pair of treatments is still relatively small. Furthermore, for some treatments there was no direct comparative research. Consequently, traditional pairwise meta-analyses are limited in helping to summarise the most effective treatment among 14 kinds of treatments. The ability to estimate effectiveness in this work using network meta-analysis allows for more comprehensive assessment of treatment options than has been previously possible. treatments, and we cannot make a definitive conclusion about the superiority of one treatment over another. Supplementary appendix 4, table S4.3 presents the eradication rates of different countries calculated by network meta-analyses.

Visual inspection of funnel plots for the primary outcomes did not show distinct asymmetry (see supplementary appendix 4, fig S4.1).

\section{Discussion}

This network meta-analysis has four principal findings: the previously recommended seven days of standard triple treatment was the least effective in intention to treat analysis; prolonging the duration of treatments seems to enhance eradication rates; the concomitant treatments, 10 or 14 days of probiotic supplemented triple treatment, 10 or 14 days of levofloxacin based triple treatment, 14 days of hybrid treatment, and 10 or 14 days of sequential treatment seemed more effective than other kinds of treatments; prolonging treatment unsurprisingly seemed to increase the risk of adverse events. The two treatments that performed best in terms of adverse events were the seven days of probiotic supplemented triple treatment and seven days of levofloxacin based triple treatment.

\section{Findings in context of recommendations for standard triple treatment}

Some previous pairwise meta-analyses are aligned with our findings and showed that in some circumstances seven days of standard triple treatment is less effective than treatments such as seven days of probiotic supplemented treatment, ${ }^{35} 10$ days of bismuth

\section{Detailed consideration of better performing treatments}

Some treatments had relatively higher eradication rates and hybrid treatment. However, relatively few studies assessed these treatments. Only three studies including 504 participants compared the efficacy of seven days of concomitant treatment with that of other treatments, and three studies including 940 participants compared 14 days of hybrid treatment with other treatments. Therefore the validity of conclusions drawn about these treatments is somewhat limited. There is a need for larger and well designed studies to assess less studied treatments so valid conclusions can be made about the most effective and least harmful treatments. This may be particularly relevant for treatments such as the seven days of concomitant treatment, which had the highest efficacy and yet no worse adverse events profile than many of the other 10 or 14 day treatments (fig 6).

Ten or 14 days of sequential treatment was another popularly studied treatment that performed well. ${ }^{637}$ As would be expected, this treatment was virtually identical to the seven days of standard triple treatment for risk of adverse events but did display improved efficacy of eradication. Differences between 10 or 14 days of concomitant treatment, 14 days of hybrid treatment, and 10 or 14 days of sequential treatment were not statistically significant, thus revealing similar efficacies of these regimens. The similar efficacy of concomitant, hybrid, and sequential treatments was also reported in a previously published pairwise meta-analysis. ${ }^{24}$ in this study-for example, the concomitant treatments 
Our study demonstrated that adding probiotics to standard triple treatment had the positive consequence of enhancing efficacy, and previous systematic reviews reached the same conclusion..$^{42}$ In addition, our study revealed that seven days of probiotic supplemented triple treatment performed the best in the tolerance analysis. Probiotics are viable microorganisms that have health benefits beyond general nutrition if ingested in sufficient numbers. ${ }^{4344}$ They exhibit important and wide ranging in vitro antibacterial activity against enteric bacteria. ${ }^{4344}$ Additionally, probiotics stimulate defensive acidogenic flora, induce lymphatic proliferation, modulate non-specific and specific immune responses to pathogens, as well as increase specific IgA responses, all of which are potential mechanisms for the efficacy and tolerance of probiotic supplemented treatment. ${ }^{445}$ However, several things should be considered before recommending probiotics in clinical practice. First of all, only seven studies used 10 or 14 days of probiotic supplemented triple treatment, and the sample sizes were small, ranging from 17 to 98 participants. The roles of probiotics in these studies are unclear, and different results may be due to the different timing of probiotic administration or to the duration of probiotic use. Different kinds of probiotics may also produce different effects. In addition, the quality of evidence from treatments including probiotic supplementation was generally poor, with only five of 17 studies clearly indicating that participants were blind to allocation. Lack of blinding is likely to influence compliance and reporting of adverse events, and in a large proportion of all included studies in this review a major weakness was the lack of or poor reporting about blinding of participants. Furthermore, the total adverse event rate for 10 or 14 days of probiotic supplemented triple treatment was only reported by small numbers of studies. Therefore, before we can safely conclude about the efficacy and tolerance profile of the probiotic supplemented triple treatments, more well designed double blind randomised controlled trials with large sample sizes should be conducted. Whether probiotics can help to improve efficacy of treatments such as the concomitant treatment, or other treatments, needs more research.

Contradictory results were sometimes observed for the same treatments between studies included in this review: the same regimen may prove to be extremely effective in one geographical area but have disappointing results in another, indicating that each treatment might have its own preferred application condition and limitations. For instance, sequential treatment proved ineffective in patients with dual resistance to clarithromycin and imidazole, ${ }^{46}$ and concomitant treatment seemed to be a better choice. ${ }^{47}$ The difference in the rates of antibiotic resistance in different geographical areas, especially the resistance to clarithromycin and metronidazole between groups is probably one of the main explanations for contrasting results. ${ }^{4849}$ In addition, even in the same geographical region, differences in results may occur, making it challenging to identify the "best" treatment. However, a large portion of the included studies did not conduct antibiotic resistance or sensitivity tests before allocation of treatments, and some studies tended to only mention the antibiotic resistance rates in their countries in general. This could cause selection bias and a baseline difference in resistance to antibiotics between groups. Because of the lack of information on antibiotic resistance, it was not possible for us to conduct a meta-regression analysis or a subgroup analysis to evaluate the extent to which each study's antibiotic resistance rates contribute to heterogeneity of treatment effects.

\section{Strengths and weaknesses of this review}

First and foremost this study is the most comprehensive and systematic comparative meta-analysis of eradication treatments for $\mathrm{H}$ pylori. After rigorous and detailed searching, we identified 143 studies including 32056 patients to contribute data to this work. Moreover, using the network meta-analysis, we were able to assess multiple treatments and to provide a rank order for treatments based on their capacity to eradicate $H$ pylori and the likelihood to cause adverse events. ${ }^{50}$

Our study has several limitations. The quality of included studies is the principal limitation in any findings generated through meta-analysis. ${ }^{31}$ In addition to the lack of information about random sequence generation, blinding, and other useful information, a large portion of studies did not assess the antibiotic sensitivity or resistance of $H$ pylori. Thus a baseline difference in resistance to antibiotics between groups cannot be ruled out. Different types or rates of antibiotic resistance might account for some degree of discrepancy between different study outcomes. ${ }^{49}$ Additionally, the treatments were divided into 14 kinds and studies varied in terms of proton pump inhibitor type, antibiotic agents, drug doses, and administration frequency. Other key information on potential effect modifiers such as smoking rates and alcohol consumption were generally not well reported in the studies. These factors may affect the clinical outcomes in the network analysis and cause inconsistency and heterogeneity. ${ }^{18}$ Although we used a loop specific method and found most loops to be consistent, we cannot rule out the possibility of inconsistency because of the presence of many underpowered and correlated tests in using this method. ${ }^{34}$ Moreover, because of the great variety in terms of study design, antibiotic type, dose, and administration frequency of the drugs, and the poor reporting of potential effect modifiers such as smoking and alcohol use, we could not account for all factors in the meta-regression and subgroup analyses. Our results are limited in this regard. In addition, evidence in this network meta-analysis largely originated from countries in East Asia, the Middle East, and Europe, with fewer from other regions. The better treatment regimens identified in this work may therefore not be applicable to other regions such as South East Asia, South America, middle Asia, and Africa, and further studies from these regions are welcomed. Furthermore, treatments such as hybrid and concomitant treatments have not been extensively studied. The numbers of studies and the sample sizes 
focusing on these treatments were small. Because of small numbers of studies reporting on many treatments, any conclusions made here are based on limited information. The bias from the small numbers of studies could act in either direction to exaggerate or underestimate effect sizes. Moreover, many included studies did not provide information on the reasons for patients' withdrawal, or poorly reported the adverse events. In less researched treatments, assessment of separate adverse events is limited by small numbers of such events, and so overall adverse events may represent a more reliable impression of treatment harms.

\section{Implications}

Balancing the evidence of greater effectiveness and the accompanying increasing risk of harms with longer duration of treatment is a crucial problem in the treatment of $H$ pylori infection and should have a bearing in clinical practice guidelines that might result from this work. The concomitant treatments, 10 or 14 days of probiotic supplemented triple treatment, 10 or 14 days of levofloxacin based triple treatment, 14 days of hybrid treatment, and 10 or 14 days of sequential treatment performed better in terms of efficacy. The credible intervals in outcome ranks were wide, indicating overlapping degrees of effectiveness for many treatments; therefore, a choice of any treatment should also be based on other factors, such as status of local antibiotic resistance, costs, availability of medicines, and safety. Although most of the differences in adverse events were not statistically significant, there is a trend for greater occurrence with longer treatment.

The important problem of local resistance to antibiotics needs to be tackled in future work, with studies quantifying local resistance rates. In particular, the efficacies of the same treatment with different antibiotics could be examined.

A major challenge in interpreting results from these many studies is that the resistance profile by region is likely to be different, meaning that one single "most effective" treatment is unlikely to be identified across the world, as the treatments will need to be tailored to regional resistance profiles. An important limitation with the included studies is that the resistance was not measured and also only a small proportion of the studies originated in South East Asia, South America, middle Asia, or Africa. The efficacy results here must be interpreted in this context and will be more relevant to those regions contributing large numbers of studies to the analysis. Consequently, we are unable to draw conclusions about the "best" treatment for regions where few studies have been conducted; and even for those regions with many studies, findings are limited by the unquantified antibiotic resistance of study populations.

\section{Conclusions}

This comprehensive network meta-analysis showed that the previously widely used seven days of standard triple treatment, although effective, was out-performed in effectiveness by most other treatments. Treatments such as the concomitant ones, the 10 or 14 days of probiotic supplemented triple treatment, 10 or 14 days of levofloxacin based triple treatment, 14 days of hybrid treatment, and 10 or 14 days of sequential treatment might be optimal alternatives. Prolonging the duration of treatments for longer than seven days seems to significantly enhance eradication rates but may increase the rates of adverse events. However, different regions are likely to have different features of $H$ pylori resistance to antibiotics and findings from the smaller number of studies that have examined these apparently more effective treatments may not apply to other locations. $H$ pylori eradication was more often studied in regions such as China, South Korea, southern Europe, and the Middle East, with relatively few in other areas. Therefore, more well designed randomised controlled trials in different countries, with large sample sizes and that include tests for antibiotic resistance are crucial to enable assessment of these varying treatments.

\section{AUTHOR AFFILIATIONS}

${ }^{1}$ Department of Epidemiology and Biostatistics, School of Public Health, Anhui Medical University, Hefei, Anhui, People's Republic of China

${ }^{2}$ Anhui Provincial Laboratory of Population Health and Major Disease Screening and Diagnosis, Anhui Medical University, Hefei, Anhui, People's Republic of China

${ }^{3}$ Division of Epidemiology, The Jockey Club School of Public Health and Primary Care, The Chinese University of Hong Kong, Hong Kong, China

4Department of Gastroenterology, Zhongshan Hospital, Fudan University, Shanghai, People's Republic of China

5Department of Gastroenterology, the First Affiliated Hospital of Anhui Medical University, Hefei, Anhui, People's Republic of China ${ }^{6}$ The Second Affiliated Hospital of Anhui Medical University, Hefei, Anhui, People's Republic of China

${ }^{7}$ The Hong Kong Branch of The Chinese Cochrane Centre, The Chinese University of Hong Kong, Hong Kong, China

Contributors: CM and D-QY conceived the study. BZL, CZ, QLY, and PL collected the data. BZL, JQY, and BG analysed and interpreted the data. BZL drafted the manuscript. BZL, DET, and CM critically revised the manuscript for important intellectual content. JYW, JMX, and JQY provided technical support. All authors commented on the drafts and approved the final draft. CM and D-QY are the guarantors. CM (maochen@cuhk.edu.hk) and D-QY (ydq@ahmu.edu.cn) contributed equally to this work and should be considered as co-corresponding authors.

Funding: This systematic review was funded by the Chinese national high level personnel special support plan.

Competing interests: All authors have completed the ICMJE uniform disclosure form at www.icmje.org/coi_disclosure.pdf (available on request from the corresponding author) and declare: this work was funded by the Chinese national high level personnel special support plan; there were no financial relationships with any organization that might have an interest in the submitted work in the previous three years and no relationships or activities that could appear to have influenced the submitted work.

Ethical approval: Not required.

Data sharing: No additional data available.

Transparency: The lead authors (CM and D-QY) affirm that the manuscript is an honest, accurate, and transparent account of the study being reported; that no important aspects of the study have been omitted; and that any discrepancies from the study as planned (and, if relevant, registered) have been explained.

This is an Open Access article distributed in accordance with the Creative Commons Attribution Non Commercial (CC BY-NC 4.0) license, which permits others to distribute, remix, adapt, build upon this work non-commercially, and license their derivative works on different terms, provided the original work is properly cited and the use is noncommercial. See: http://creativecommons.org/licenses/by-nc/4.0/. 
1 Marshall BJ, Warren JR. Unidentified curved bacilli in the stomach of patients with gastritis and peptic ulceration. Lancet 1984;1:1311-5.

2 Testerman TL, Morris J. Beyond the stomach: an updated view of Helicobacter pylori pathogenesis, diagnosis, and treatment. World J Gastroenterol 2014;20:12781-808.

3 Linz B, Balloux F, Moodley Y, et al. An African origin for the intimate association between humans and Helicobacter pylori. Nature 2007:445:915-8.

4 McColl KE. Clinical practice. Helicobacter pylori infection. N Engl/ Med 2010;362:1597-604

5 Malfertheiner P, Megraud F, O'Morain CA, et al. Management of Helicobacter pylori infection-the Maastricht IV/Florence consensus report. Gut 2012;61:646-64.

6 Gatta L, Vakil N, Vaira D, Scarpignato C. Global eradication rates for Helicobacter pylori infection: systematic review and meta-analysis of sequential therapy. BMJ 2013;347:44587.

7 Georgopoulos SD, Papastergiou V, Karatapanis S. Current options for the treatment of Helicobacter pylori. Expert Opin Pharmacother 2013;14:211-23.

8 Eusebi LH, Zagari RM, Bazzoli F. Epidemiology of Helicobacter pylori infection. Helicobacter 2014;19(Suppl 1):1-5.

9 Fakheri H, Bari Z, Aarabi M, Malekzadeh R. Helicobacter pylori eradication in West Asia: a review. World I Gastroenterol 2014;20:10355-67.

10 Den Hollander WJ, Holster IL, den Hoed CM, et al. Ethnicity is a strong predictor for Helicobacter pylori infection in young women in a multi-ethnic European city. J Gastroenterol Hepatol 2013;28:1705-11.

11 Malfertheiner P, Mégraud F, O'Morain C, et al. Current concepts in the management of Helicobacter pylori infection-the Maastricht 2-2000 consensus report. Aliment Pharmacol Ther 2002;16:167-80.

12 Ungan M, Kulaçollu H, Kayhan B. Cure rates obtained with five different Helicobacter pylori eradication protocols in patients with duodenal ulcer: a prospective, open-label, randomized study in a primary care setting in Turkey. Curr Ther Res Clin Exp 2001:462-72.

13 Graham DY, Fischbach L. Helicobacter pylori treatment in the era of increasing antibiotic resistance. Gut 2010;59:1143-53.

14 Malfertheiner P, Megraud F, O'Morain C, et al. Current concepts in the management of Helicobacter pylori infection: the Maastricht III consensus report. Gut 2007; 56:772-81.

15 Moayyedi P. Sequential regimens for Helicobacter pylori eradication. Lancet 2007;370:1010-2.

16 Valooran GJ, Kate V, Jagdish S, Basu D. Sequential therapy versus standard triple drug therapy for eradication of Helicobacter pylori in patients with perforated duodenal ulcer following simple closure. Scand I Gastroenterol 2011;46:1045-50.

17 Kadayifci A, Uygun A, Polat Z, et al. Comparison of bismuth-containing quadruple and concomitant therapies as a first-line treatment option for Helicobacter pylori. Turk J Gastroenterol 2012;23:8-13.

18 Ye CL, Liao GP, He S, Pan YN, Kang YB, Zhang ZY. Levofloxacin and proton pump inhibitor-based triple therapy versus standard triple first-line therapy for Helicobacter pylori eradication. Pharmacoepidemiol Drug Saf 2014:23:443-55.

19 Du YQ, Su T, Fan JG, et al. Adjuvant probiotics improve the eradication effect of triple therapy for Helicobacter pylori infection. World ) Gastroenterol 2012;18:6302-7.

20 Song MJ, Park DI, ParkJH, et al. The effect of probiotics and mucoprotective agents on PPI-based triple therapy for eradication of Helicobacter pylori. Helicobacter 2010;15:206-13.

21 Yuan Y, Ford AC, Khan KJ, et al. Optimum duration of regimens for Helicobacter pylori eradication. Cochrane Database Syst Rev 2013;12:CD008337.

22 Dang Y, Reinhardt JD, Zhou X, Zhang G. The effect of probiotics supplementation on Helicobacter pylori eradication rates and side effects during eradication therapy: a meta-analysis. PLoS One 2014;9:e111030.

23 Gisbert IP, Calvet X. Review article: non-bismuth quadruple (concomitant) therapy for eradication of Helicobater pylori. Aliment Pharmacol Ther 2011;34:604-17.

24 Wang B, Wang YH, Lv ZF, et al. Efficacy and safety of hybrid therapy for Helicobacter pylori infection: a systematic review and meta-analysis. Helicobacter 2015;20:79-88.

25 Wang B, Lv ZF, Wang YH, et al. Standard triple therapy for Helicobacter pylori infection in China: a meta-analysis. World I Gastroenterol 2014:20:14973-85.

26 Gong EJ, Yun SC, Jung HY, et al. Meta-analysis of first-line triple therapy for helicobacter pylori eradication in Korea: is it time to change? J Korean Med Sci 2014;29:704-13.

27 Stagg HR, Zenner D, Harris RJ, Muñoz L, Lipman MC, Abubakar I. Treatment of latent tuberculosis infection: a network meta-analysis. Ann Intern Med 2014;161:419-28.

28 Yuan J, Zhang R, Yang Z, et al. Comparative effectiveness and safety of oral phosphodiesterase type 5 inhibitors for erectile dysfunction: a systematic review and network meta-analysis. Eur Urol 2013;63:902-12.

29 Jadad AR, Moore RA, Carroll D, et al. Assessing the quality of reports of randomized clinical trials: is blinding necessary? Control Clin Trials 1996;17:1-12.
30 Higgins JP, Altman DG, Gøtzsche PC, et al. The Cochrane Collaboration's tool for assessing risk of bias in randomised trials. BM/ 2011:343:d5928.

31 Higgins J, Green S. Cochrane handbook for systematic reviews of interventions, v.5.1.0. Cochrane Collaboration.Updated March 2011. www.cochrane-handbook.org.

32 Dias S, Welton NJ, Sutton AJ, Ades AE. NICE DSU technical support document 2: a generalised linear modelling framework for pairwise and network meta-analysis of randomized controlled trials. National Institute for Health and Care Excellence. Updated April 2014. www. nicedsu.org.uk.

33 Dias S, Sutton AJ, Welton NJ, Ades AE. NICE DSU technical support document 3: heterogeneity: subgroups, meta-regression, bias and bias-adjustment. National Institute for Health and Care Excellence. Updated April 2012. www.nicedsu.org.uk.

34 Chaimani A, Higgins JP, Mavridis D, Spyridonos P, Salanti G. Graphical tools for network meta-analysis in STATA. PLoS One 2013;8:e76654

35 Zhu R, Chen K, Zheng YY, et al. Meta-analysis of the efficacy of probiotics in Helicobacter pylori eradication therapy. World ) Gastroenterol 2014:20:18013-21.

36 Venerito M, Krieger T, Ecker T, Leandro G, Malfertheiner P. Meta-analysis of bismuth quadruple therapy versus clarithromycin triple therapy for empiric primary treatment of Helicobacter pylori infection. Digestion 2013;88:33-45

37 Kim JS, Ji JS, Choi H, Kim JH. Sequential therapy or triple therapy for Helicobacter pylori infection in Asians: systematic review and meta-analysis. Clin Res Hepatol Gastroenterol 2014;38:118-25.

38 Ching SS, Sabanathan S, Jenkinson LR. Treatment of Helicobacter pylori in surgical practice: a randomised trial of triple versus quadruple therapy in a rural district general hospital. World ) Gastroenterol 2008;14:3855-60

39 Hung IF, Chan P, Leung S, et al. Clarithromycin-amoxycillincontaining triple therapy: a valid empirical first-line treatment for Helicobacter pylori eradication in Hong Kong? Helicobacter 2009;14:505-11

40 Aydin A, Onder G, Akarca U, Tekin F, Tuncyurek M, Ilter T. Comparison of 1 - and 2-week pantoprazole-based triple therapies in clarithromycin-sensitive and resistant cases. Eur J Intern Med 2007:18:496-500.

41 Gisbert JP, Calvet X. Update on non-bismuth quadruple (concomitant) therapy for eradication of Helicobacter pylori. Clin Exp Gastroenterol 2012;5:23-34.

42 Wang ZH, Gao QY, Fang JY. Meta-analysis of the efficacy and safety of Lactobacillus-containing and Bifidobacterium-containing probiotic compound preparation in Helicobacter pylori eradication therapy. Clin Gastroenterol 2013:47:25-32.

43 Urdaci MC, Bressollier P, Pinchuk I. Bacillus clausii probiotic strains: antimicrobial and immunomodulatory activities. J Clin Gastroenterol 2004;38:S86-90.

44 Zou J, Dong J, Yu X. Meta-analysis: Lactobacillus containing quadruple therapy versus standard triple first-line therapy for Helicobacter pylor eradication. Helicobacter 2009;14:97-107.

45 Erickson KL, Hubbard NE. Probiotic immunomodulation in health and disease. J Nutr 2000;130:403S-09S.

46 Vaira D, Zullo A, Vakil N, et al. Sequential therapy versus standard triple-drug therapy for Helicobacter pylori eradication: a randomized trial. Ann Intern Med 2007;146:556-63.

47 Wu DC, Hsu PI, Wu JY, et al. Sequential and concomitant therapy with four drugs is equally effective for eradication of $\mathrm{H}$ pylori infection. Clin Gastroenterol Hepatol 2010;8:36-41 e1.

48 Liou JM, Chen CC, Chen MJ, et al. Sequential versus triple therapy for the first-line treatment of Helicobacter pylori: a multicentre, open-label, randomised trial. Lancet 2013:381:205-13.

49 Greenberg ER, Anderson GL, Morgan DR, et al. 14 day triple, 5-day concomitant, and 10-day sequential therapies for Helicobacter pylor infection in seven Latin American sites: a randomised trial. Lancet 2011;378:507-14.

50 Loymans RJ, Gemperli A, Cohen J, et al. Comparative effectiveness of long term drug treatment strategies to prevent asthma exacerbations: network meta-analysis. BMJ 2014;348:g3009.

(c) BMJ Publishing Group Ltd 2015

Web Extra Web appendix 1: study selection and characteristics of included studies

Web appendix 2: references of included studies Web appendix 3: quality of included studies Web appendix 4: efficacy results of eradication treatments for Helicobacter pylori

Web appendix 5: tolerance results of eradication treatments for Helicobacter pylori 